\title{
A REFUNCIONALIZAÇÃO DO ESTADO E A POLÍTICA DA BASE NACIONAL COMUM CURRICULAR NO PROCESSO DE ATUALIZAÇÃO DAS ESTRATÉGIAS DE DOMINAÇÃO BURGUESA
}

LA REFUNCIONALIZACIÓN DEL ESTADO Y LA POLÍTICA DE LA BASE CURRICULAR NACIONAL COMÚN EM EL PROCESO DE ACTUALIZACIÓN DE LAS ESTRATEGIAS DE DOMINACIÓN BURGUESA

THE REFUNCTIONALIZATION OF THE STATE AND THE POLICY OF THE CURRICULAR COMMON NATIONAL BASE IN THE PROCESS OF UPDATING STRATEGIES OF BURGUIN DOMINATION

DOI: 10.22481/rbba.v1i02.7791

Danilo Bandeira dos Santos Cruz Universidade Federal de Santa Catarina - Brasil ORCID: http://orcid.org/0000-0001-5831-6698 Lattes: http://lattes.cnpq.br/5059209671590907 Endereço eletrônico: danibande2@gmail.com

Luciana Pedrosa Marcassa Universidade Federal de Santa Catarina - Brasil ORCID: https://orcid.org/0000-0001-5313-1002

ID Lattes: http://lattes.cnpq.br/6655683758937444 Endereço eletrônico: luciana.marcassa@ufsc.br

\section{RESUMO}

O presente texto versa sobre a atualização das estratégias de produção e perpetuação da hegemonia burguesa no Brasil, no contexto de crise estrutural do capitalismo e de ampliação da dominação do capital financeiro, manifesta a partir da década de 1970 e estendida aos dias atuais. Com base no referencial gramsciano, aponta que tais estratégias têm se pautado, entre outras coisas, pela manutenção e aprofundamento de reformas, realizadas sobre e por dentro do aparelho governativo do Estado, sob notável influência de grupos empresariais, organizados em 
seus aparelhos privados de hegemonia. No campo educacional, essas reformas se voltam aos interesses de tais grupos, os quais se mobilizam, entre outras coisas, no sentido da disputa por parcelas mais vultosas do fundo público. Nesse contexto, a Base Nacional Comum Curricular surge como um dos elementos de atualização deste projeto hegemônico, dentro de um plano estratégico mais amplo de reprodução das relações de dominação burguesa, com fortes acentos autoritários.

Palavras-chave: Estado; Autoritarismo; Fundo Público; Educação; BNCC.

\title{
RESUMEN
}

Este texto trata sobre la actualización de las estrategias productivas y la perpetuación de la hegemonía burguesa en Brasil, en el contexto de la crisis estructural del capitalismo y la expansión del dominio del capital financiero, manifestada desde la década de 1970 y extendida hasta la actualidad. Con base en el marco Gramsciano, señala que tales estrategias se han orientado, entre otras cosas, por el mantenimiento y profundización de reformas, realizadas en y dentro del aparato gubernamental del Estado, bajo la notable influencia de grupos empresariales, organizados en sus dispositivos privados de hegemonia. En el ámbito educativo, estas reformas están orientadas a los intereses de dichos grupos, que se movilizan, entre otras cosas, hacia la disputa por mayores montos de fondos públicos. En este contexto, la Base Curricular Común Nacional surge como uno de los elementos de actualización de este proyecto hegemónico, dentro de un plan estratégico más amplio de reproducción de las relaciones de dominación burguesa, con fuertes acentos autoritarios.

Palabras clave: Estado. Autoritarismo. Fondo Público. Educación. BNCC.

\begin{abstract}
This text deals with the updating of production strategies and the perpetuation of bourgeois hegemony in Brazil, in the context of the structural crisis of capitalism and the expansion of the domination of financial capital, manifested from the 1970s and extended to the present day. Based on the Gramscian framework, pointing out that such strategies have been guided, among other things, by the maintenance and deepening of reforms, carried out on and within the governmental apparatus of the State, under the notable influence of business groups, organized in their private devices of hegemony. In the educational field, these reforms are aimed at the interests of such groups, which mobilize themselves, among other things, towards the dispute over larger amounts of public funds. In this context, the National Common Curricular Base emerges as one of the elements of this hegemonic project update, within a broader
\end{abstract}


COMUM CURRICULAR NO PROCESSO DE ATUALIZAÇÃO DAS

ESTRATÉGIAS DE DOMINAÇÃO BURGUESA

strategic plan for the reproduction of bourgeois domination relations, with strong authoritarian accents.

Keywords: State; Authoritarianism; Public Fund; Education; NCCB.

\section{INTRODUÇÃO}

Este artigo é parte de uma pesquisa em andamento, cujo objetivo é analisar o papel da União Nacional dos Dirigentes Municipais de Educação - UNDIME no processo de definição e implementação de políticas educacionais no Brasil, no contexto de crise estrutural do capital e do consequente movimento de ampliação do Estado, no período de 1980 a 2020, com destaque à política curricular, expressa pela Base Nacional Comum Curricular - BNCC. Neste texto em específico, pretende-se discutir a reconfiguração do Estado diante das atualizadas estratégias de produção e manutenção da hegemonia burguesa, sobretudo, ao longo do movimento histórico de ascensão do capital financeiro.

A reflexão está organizada em três partes, no âmbito das quais se efetivou o desenvolvimento do conteúdo proposto, iniciado a partir de discussões direcionadas à compreensão do complexo movimento mais recente de crise estrutural do capital que se arrasta desde os anos de 2007-2008 e que se aprofunda dramaticamente, em razão da pandemia pelo novo coronavírus, a qual alterou, de modo significativo, a dinâmica do sistema capitalista. Nessa direção, as intervenções do Estado em favor dos interesses de produção e manutenção da hegemonia burguesa, apesar das resistências por parte dos trabalhadores, são postas em evidência para pensarmos a relação entre força e consenso no processo de desenvolvimento de um "novo regime de acumulação" (HARVEY, 2016), com destaque às medidas autoritárias impostas à sociedade, reverberadas em novas e constantes expropriações, segundo Fontes (2010).

Em seguida, o texto traz a particularidade brasileira no contexto de redemocratização, associado ao ascenso do neoliberalismo e, por extensão, do capital monopolista. Assim, demonstra o poder de interferência nas políticas econômicas e sociais da fração rentista da classe dominante no país, impondo uma série de reformas, através de uma contínua articulação com a sociedade política. Trata-se de um processo que, segundo Castelo (2017), resulta da "violência como potência econômica", categoria utilizada por Marx (1989) para analisar a 
A REFUNCIONALIZAÇÃO DO ESTADO E A POLÍTICA DA BASE NACIONAL

COMUM CURRICULAR NO PROCESSO DE ATUALIZAÇÃO DAS

ESTRATÉGIAS DE DOMINAÇÃO BURGUESA

dinâmica de desenvolvimento do capitalismo em seu estágio primitivo. Nesse sentido, é posto em relevo o papel do fundo público e do seu par, a dívida pública, na dinâmica de reprodução ampliada do capital.

$\mathrm{Na}$ terceira parte, a atenção se volta ao campo educacional institucionalizado, sinalizando a BNCC como elemento de atualização das estratégias de dominação da burguesia. $\mathrm{O}$ estudo do processo de definição e implementação da BNCC revela que, contando com o beneplácito da sociedade política, diversos intelectuais coletivos ligados ao setor empresarial criaram o Movimento pela Base, grupo não governamental que reúne instituições e pessoas físicas interessadas no campo da educação, com vistas a definir os rumos da política curricular brasileira desde 2013. Contudo, se as reformas em geral e, particularmente as educacionais, vinham sendo, até então, objeto de debates aparentemente mais democráticos ${ }^{\mathrm{i}}$, com o golpe parlamentar de 2016 e, posteriormente, a eleição do Presidente Jair Messias Bolsonaro, a força se sobrepõe ao consenso para garantir a manutenção da hegemonia rentista, com efeitos nefastos em termos de políticas econômicas e sociais, criadas e realizadas de forma mais violenta do que consensual. Exemplo disso foi a reforma do regime previdenciário, efetivada através da Emenda Constitucional № 103 de 12 de novembro de 2019, bem como as alterações na Consolidação das Leis Trabalhistas, definidas com a Lei $N^{\circ} 13.874 / 19$, denominada de Lei da Liberdade Econômica, impostas à sociedade, apesar dos inúmeros protestos contrários ocorridos em todo o país. Os efeitos dessas mudanças combinam o aprofundamento da concentração de renda e a piora efetiva das condições de vida das classes subalternas, ao passo que atendem, sobremaneira, aos interesses privados de setores ligados ao capital financeiro.

A perspectiva teórica definida para desenvolver o percurso reflexivo aqui proposto se pauta principalmente pelo pensamento marxista do filósofo italiano Antonio Gramsci, cujos textos e escritos são fundamentais para entendermos a configuração e o funcionamento do Estado, de modo particular, do próprio movimento mais amplo do capital em seu estágio monopolista.

\section{Capitalismo em crise e a atuação do Estado sob a égide do neoliberalismo}

A escrita deste artigo se passa no espaço-tempo marcado pelo acelerado crescimento do ritmo de contaminação do novo Coronavírus, causador de doença respiratória aguda e que já provocou a morte de 1.316.994 pessoas, além do contágio de mais de 54.000 .000 em todo o 
A REFUNCIONALIZAÇÃO DO ESTADO E A POLÍTICA DA BASE NACIONAL

COMUM CURRICULAR NO PROCESSO DE ATUALIZAÇÃO DAS

ESTRATÉGIAS DE DOMINAÇÃO BURGUESA

mundo (WORLD HEALTH ORGANIZATION, 2020), desde que o primeiro caso foi reportado na data do dia 31 de dezembro de 2019 na cidade chinesa de Wuhan. Após o dia 11 de março deste ano, quando a Organização Mundial da Saúde - OMS declarou a pandemia de Covid-19, autoridades de saúde de diferentes países, fundamentadas na ciência, recomendaram a adoção de medidas voltadas ao isolamento social como forma de 'achatar a curva da transmissão' ou, em outros termos, reduzir a velocidade de propagação do vírus, tendo em vista a não sobrecarga dos sistemas de saúde, muito embora líderes de algumas nações, incluindo o Brasil, tenham resistido à aplicação dessas orientações, sob a alegação da necessidade de se proteger a economia. Afinal, parafraseando uma recente campanha do governo central brasileiro, 'o capitalismo não pode parar'.

Destarte, a crise do coronavírus reverberou-se no aprofundamento da crise do sistema capitalista, a qual se arrasta desde os idos de 2007-2008. Nesse sentido, os impactos econômicos e sociais, ampliados pela pandemia, assumem contornos bastante singulares, mas já sinalizam uma agudeza comparável ao dramático contexto de 1929 (FARIZA, 2020). Essas informações, alardeadas aos quatro cantos pela grande mídia nacional e internacional, expressam a grande preocupação dos agentes do capital em relação à redução das suas taxas de lucro, ao passo que eclipsam, de modo geral, o cerne do problema, isto é, nas palavras de Mészáros (2005), a própria dinâmica sociometabólica do capital, cuja ancoragem se pauta no histórico processo contraditório de socialização da produção e, de modo complementar, de sua apropriação privada, tendo por corolário a atualização das suas massivas formas de expropriações sociais. Formas estas lapidadas pela desastrosa doutrina neoliberal, tornada hegemônica desde os anos de 1970 como estratégia de reestruturação do capital.

Com efeito, o final da década de 1960 expressou "uma nova e aguda crise estrutural" que devastou o sistema capitalista, numa clara manifestação do ocaso do fordismo, bem como do Estado de bem-estar social, os quais constituíram o período "conhecido como os 30 anos gloriosos" (BOSCHETTI, 2010, p. 69). Os desdobramentos desse processo, fez emergir, nas palavras de David Harvey, "um regime de acumulação inteiramente novo, associado com um sistema de regulamentação política e social bem distinta" (2016, p. 140), ou seja, o chamado regime flexível, derivado da experiência japonesa do sistema toyotista (ANTUNES e PINTO, 2017). Se no período do fordismo/keynesianismo, a combinação entre lutas de classe, socialismo soviético e necessidade de alteração dos rumos da economia política clássica póscrise de 1929 impeliram a materialização de medidas governamentais direcionadas à expansão 
COMUM CURRICULAR NO PROCESSO DE ATUALIZAÇÃO DAS

ESTRATÉGIAS DE DOMINAÇÃO BURGUESA

dos direitos sociais nos países centrais do capitalismo, as respostas neoliberais se consolidaram na contramão dessas conquistas.

Sustentados pelas teorias de grandes intelectuais liberais, como Friedrich Hayek, Karl Popper, Milton Friedman e James Buchanan (BRESSER-PEREIRA, 2017, p. 698 apud FREITAS 2018, p. 13), o thatcherismo na Inglaterra e o reaganismo nos Estados Unidos, já sob a pressão do capital financeiro, se constituíram como os principais referenciais políticoideológicos das últimas décadas do século passado. As suas influências foram e continuam determinantes para o movimento de refuncionalização do Estado, cujos direcionamentos se dão, segundo Montaño e Durigueto (2011), por "três caminhos centrais":

a) a criação de áreas de superlucros fora da superprodução e do subconsumo (fundamentalmente via privatizações de empresas estatais); b) a extrema centralização do capital, acentuando o domínio dos monopólios no mercado (particularmente via fusões); c) a redução dos custos de produção para o capital - com o trabalho (via subcontratação, reforma da previdência, flexibilização das leis trabalhistas, recortes do financiamento estatal na área social etc.) e com os custos gerais da produção/comercialização (fundamentalmente via reforma tributária, abertura de fronteiras dos Estados nacionais para a circulação de mercadorias, automação e reengenharia etc.) (p. 192).

Como se vê, sobretudo em momentos de crises do capitalismo, a atuação do Estado, constantemente atualizada em função dos condicionantes históricos, assume o caminho prevalente da garantia da satisfação dos interesses de frações da classe burguesa, embora não de maneira a desconsiderar completamente as necessidades dos trabalhadores. Em outros termos, não se trata da negação completa das demandas societárias, visto que, no âmbito da estratégia de dominação burguesa, há de se fazer determinados sacrifícios de ordem econômicocorporativa (GRAMSCI, 2000), ou seja, algumas concessões para se garantir a coesão social. Para tanto, uma das principais medidas adotadas pelos governos são as reformas, anunciadas como necessidade fundamental para que as crises sejam superadas e, com isso, o interesse da sociedade, em seu conjunto, possa ser alcançado. Concretamente, entretanto, essas conformações estatais não passam de estratégias para a redefinição e atualização do processo de dominação político-ideológico (CASIMIRO, 2018, p. 17).

Esse movimento estratégico adquiriu características específicas ao longo da década de 1970, quando o fundo público, ou seja, a parcela de mais-valia convertida em tributos, se constituiu em ponto nevrálgico para a dinâmica de reprodução ampliada do capital e, com isso, 
COMUM CURRICULAR NO PROCESSO DE ATUALIZAÇÃO DAS

ESTRATÉGIAS DE DOMINAÇÃO BURGUESA

ampliou-se também o campo das lutas de classe, através da constante disputa por esse fundo. Nessa correlação de forças, o redesenho do Estado, sugerido, precipuamente, pelos liberais, teve “como horizonte o 'Estado mínimo', o que efetivamente significa o Estado máximo para o capital” (NETO, 2001 apud LUPATINI, 2012, p. 60). Para Lupatini (2012, pp. 60-61), as "evidências constitutivas dessas políticas" liberalizantes, que ajudam a elucidar as ações governamentais de apoio à manutenção dos interesses mais amplos do capital, podem ser assim sinalizadas:

Por um lado, liberalização e desregulamentação dos fluxos de capital, privatização das empresas estatais, instrumentos e medidas para reforçar a propriedade privada, políticas monetárias e fiscais restritivas etc., por outro lado, assalto à seguridade social, aos direitos sociais conquistados pela classe trabalhadora no pós-guerra, flexibilização das leis trabalhistas etc.

Todo esse conjunto de ações combinadas, em que à classe trabalhadora é imposta uma série de medidas de austeridade, tornando-a ainda mais vulnerável e, por conseguinte, comprometendo, tanto a sua condição de existência, quanto a sua luta, é parte indissociável do movimento do capital, sobretudo, em seu atual estágio monopolista, no qual o capital financeiro, "configurando a generalização do capital portador de juros", detém a hegemonia. Trata-se da manutenção e da recriação de expropriações primárias e secundárias ${ }^{\mathrm{ii}}$, derivadas do permanente movimento de concentração de recursos sociais "sob a forma monetária" cujo sentido alcança a produção de imensas levas de trabalhadores disponíveis no mercado de trabalho (FONTES, 2010), vale dizer, trabalhadores explorados, desprotegidos e violentados em seus direitos e necessidades.

\section{O neoliberalismo e o autoritarismo estatal na particularidade brasileira}

No contexto brasileiro, esse processo de ascenso do neoliberalismo foi mais evidente durante os anos de 1990, em especial, ao longo dos governos do ex-presidente Fernando Henrique Cardoso (1995-2002), os quais se pautaram por uma ampla reforma do Estado ${ }^{\mathrm{iii}}$, que se refletiu diretamente no campo das políticas públicas, como um verdadeiro movimento de ataque aos direitos conquistados pelos trabalhadores. Cabe afirmar que, apesar do perfil progressista dos subsequentes governos petistas (Lula da Silva - 2003-2010 e Dilma Rousseff - 2011-2016), a política direcionada ao capital financeiro não foi modificada, muito embora a 
COMUM CURRICULAR NO PROCESSO DE ATUALIZAÇÃO DAS

ESTRATÉGIAS DE DOMINAÇÃO BURGUESA

sua adesão em tal período tenha assumido características particulares, haja vista a sua maior aproximação com os movimentos sociais e o claro arrefecimento das privatizações (BOSCHETTI, 2010).

Em seu esforço de refletir sobre esse período, configurado pelo forte avanço do capital financeiro, Castelo (2017) recorre à categoria, usada por Marx (1989), de violência como potência econômica, através da qual revela as táticas e as estratégias usadas pela hegemônica fração rentista do bloco no poder, numa atuação conjunta com a sociedade política, para garantir e revitalizar a condição de profunda dependência econômica e política da classe operária e do campesinato (CASTELO, 2017, p. 61). Nessa perspectiva, em que o Estado se amplia com a "refuncionalização de antigas estruturas e criação de novas" (p. 61), com vistas a blindar os interesses das classes dominantes, a violência como potência econômica cumpre a função de disciplinar os subalternos, via processo de deterioração de suas condições de sobrevivência. A sua manifestação concreta se dá da seguinte maneira:

privatização dos ativos públicos com farto financiamento estatal, política monetária de juros altos, liberalização das contas internacionais, expropriação tributária dos salários e aposentadorias, política fiscal direcionadora do fundo público para os fundos privados dos donos da dívida pública, isenções fiscais bilionárias, programas sociais que capitalizam empreendimentos privados, retirada de direitos sociais, intervenções nos sindicatos, expropriações dos meios de produção dos povos originários, ocupações militares de comunidades populares etc. (CASTELO, 2017, p. 63).

O autor segue a sua explanação demonstrando como a supremacia rentista no Brasil foi sendo consumada, com uma atuação determinante do Estado, que a partir do receituário neoliberal anunciado pelo Consenso de Washington, conformou-se para garantir a perpetuação de tal supremacia. Assim, desde 1993 uma série de medidas legislativas foram criadas como forma de legitimar esse processo, dentre as quais destacam-se:

(1) a Desvinculação de Receitas da União (criada como Fundo Social de Emergência, depois Fundo de Estabilização Fiscal), que recentemente aumentou de 20 para 30\%; (2) a Lei de Responsabilidade Fiscal (2000); e (3) a nova Lei de Falências (2005). Com esta legislação, o Estado definiu como prioridade máxima o pagamento dos juros e amortizações da dívida pública, garantindo altas taxas de rentabilidade para os setores rentistas das classes dominantes (CASTELO, 2017, p. 64). 
COMUM CURRICULAR NO PROCESSO DE ATUALIZAÇÃO DAS

ESTRATÉGIAS DE DOMINAÇÃO BURGUESA

Os governos progressistas do Partido dos Trabalhadores deram continuidade a essas ações liberalizantes, que marcam uma acirrada disputa intra e entre classes pela maior parcela possível do fundo público, com nítida desvantagem à classe trabalhadora. Em 2016, a partir do "golpe legislativo-midiático-judiciário" houve uma reconstituição do bloco no poder, num momento em que a Presidência da República foi, de forma antidemocrática, ocupada por Michel Temer, do Movimento Democrático Brasileiro - MDB, o qual se comprometeu com a renovação e o fortalecimento do pacote de reformas que, na prática, se efetivou com privatizações, alteração na Consolidação da Legislação Trabalhista - CLT, por meio da Lei No 13.467 de 13 de julho de 2017 e, um ano antes, com a aprovação da Emenda Constitucional 95, que congelou os gastos públicos por 20 anos (CASTELO, 2017). Tais medidas foram implementadas sob a alegação da necessária superação da crise fiscal brasileira, mas evidenciaram o grau de violência do Estado contra as classes subalternas, cada vez mais lançadas a condições precárias de sobrevida. Esse processo concorre à compreensão dos motivos pelos quais os serviços de saúde, assistência social e educação tenham tido verbas cada vez mais escassas nos orçamentos públicos, enquanto vultosas somas de recursos, provenientes da arrecadação tributária, que recai principalmente sobre os mais pobres, são direcionadas à composição de superávit primário, com vistas a ampliar a acumulação de capital pelos insaciáveis grupos de rentistas, em especial, via ampliação da dívida pública.

Nessa direção, pode-se afirmar que a dívida pública, responsável por assegurar o maior acesso ao fundo público por parte dos seus compradores, se configura como elemento central de perpetuação do sistema capitalista. Principalmente em períodos de crise, a forma encontrada pelo capital para retomar o seu processo de acumulação passa pela garantia de acesso à maior parcela possível do fundo público, feito, como se vê, de modo expressamente autoritário. Para tanto, são adotadas medidas para reativar a valorização do capital, entre as quais estão as privatizações, as reformas tributária, trabalhista, previdenciária e, inclusive, educacional. Ora, esse quadro de ações governamentais, voltadas aos interesses privatistas, expõe a maneira encontrada pelo próprio capital para promover o reequilíbrio do seu sistema econômico a partir do direcionamento das ações do Estado, o que corrobora a tese gramsciana sobre a materialidade do Estado integral ${ }^{\text {iv }}$ (GRAMSCI, 2000). 
A REFUNCIONALIZAÇÃO DO ESTADO E A POLÍTICA DA BASE NACIONAL

COMUM CURRICULAR NO PROCESSO DE ATUALIZAÇÃO DAS

ESTRATÉGIAS DE DOMINAÇÃO BURGUESA

\section{A relação força-consenso no campo educacional brasileiro e a política curricular expressa pela BNCC}

Essa forma de agir, de modo impositivo e autoritário, típica do neoliberalismo, alcança o campo educacional institucionalizado, no sentido de promover a sua legitimação, também pela via da relação força-consenso. Assim, o sistema de ações-ideias da classe burguesa vai abrindo espaço para que até mesmo a classe trabalhadora possa não somente aceitar a sua ideologia, como unívoca, mas também, para que tal classe contribua com a reprodução da sociabilidade burguesa. Isto justifica o fato de que, em muitos casos, boa parte dos explorados saia em defesa dos ajustes, propostos/impostos pelos seus exploradores, por terem incorporado esta percepção da realidade tal como ela aparenta ser. Nessa perspectiva, a doutrina neoliberal vai construindo as condições materiais para a sua realização, com base nas condições historicamente instituídas. E, nessa direção, a educação desempenha um papel fundamental.

Por isso, a mentalidade empresarial, configurada pela lógica do individualismo, da competição, da meritocracia, do empreendedorismo, da gestão gerencial, assim como da chamada governança em rede, são marcas bem presentes nos textos das reformas educacionais em curso desde os anos de 1990 e, portanto, expressam a demanda burguesa pelo controle mais rígido dos processos formativos institucionalizados. Isto favorece o entendimento sobre os motivos pelos quais grupos de empresários têm se organizado, através da criação de movimentos e organizações, para disputarem a pauta da educação e, em especial, do Currículo escolar. Bom exemplo é o Movimento pela $B^{\mathrm{v}} \mathrm{v}^{\mathrm{v}}-\mathrm{MBNC}$, financiado por importantes instituições financeiras, como o Unibanco, o Bradesco e o Santander (ANTUNES, 2017), que reuniu um grande número de intelectuais coletivos no sentido da elaboração e implementação da Base Nacional Comum Curricular no Brasil, com forte destaque à Fundação Lemann, que ocupou o lugar de direção do movimento. Ademais, o MBNC contou com as indispensáveis parcerias do Conselho Nacional de Secretários de Educação - CONSED e da União Nacional dos Dirigentes Municipais de Educação - UNDIME, duas entidades criadas na década de 1980 a partir da associação de agentes políticos do campo educacional brasileiro (NEVES, 2005), que desempenham uma função primordial no processo de produção de consensos junto aos sistemas e redes estaduais e municipais de ensino, corroborando a implantação de diferentes projetos hegemônicos.

Revista RBBA $\mid$ Revista Binacional Brasil Argentina 
COMUM CURRICULAR NO PROCESSO DE ATUALIZAÇÃO DAS

ESTRATÉGIAS DE DOMINAÇÃO BURGUESA

Essas articulações em torno da aprovação da BNCC revelam a intensificação das interferências do setor privado na esfera pública. Conforme sinaliza Saviani (2014):

A força do privado traduzida na ênfase dos mecanismos de mercado vem contaminando crescentemente a própria esfera pública. É assim que o movimento dos empresários vem ocupando espaço nas redes públicas via UNDIME e CONSED, nos Conselhos de Educação e no próprio aparelho de Estado, como o ilustram as ações do Movimento "Todos pela Educação" (p. 105).

A atuação desses intelectuais coletivos, representantes dos interesses da classe empresarial, foi bastante exitosa em relação à aprovação da BNCC. A sua participação e forte influência foram fundamentais ao longo de todo o processo de constituição do documento, que se tornou a principal referência para a dinâmica formativa dos brasileiros. A BNCC traduz um projeto de formação humana assentado sobre as bases de uma doutrina liberal reordenada, atualizada, em conformidade com as demandas de reprodução do modo de produção capitalista na contemporaneidade. Trata-se de uma perspectiva pautada na descaracterização do papel docente, sobretudo quando propõe um currículo esvaziado de conhecimentos científicos em benefício da aprendizagem por competências, cujo sucesso depende da necessária conformação docente, forjada por meio de formações aligeiradas e rasas, já propostas em 2017 pelo Ministério da Educação, a partir da reformulação de ações como o Programa Institucional de Bolsas de Iniciação à Docência - PIBID, Residência Docente e da abertura de vagas para curso de formação de professores na Universidade Aberta do Brasil - UAB (FREITAS, 2018). Somado a isso, há a desvalorização dos aspectos colaborativos e a reafirmação da concorrência, da responsabilização individual e coletiva pelos fracassos ou sucessos alcançados, conforme considerações de Giroux (2017 apud Freitas 2018):

\footnotetext{
A antiga linguagem dos direitos coletivos deu lugar ao discurso dos direitos individuais, e o vocabulário da colaboração e solidariedade foi deslocado pelo discurso do individualismo radical e o ethos áspero da sobrevivência do mais forte. A 'liberdade' se transformou em sinônimo de interesse próprio desenfreado para abdicar de qualquer senso de responsabilidade moral e política (p. 24).
}

Além da necessidade de se estabelecer o controle geral das ações pedagógicas em todo o país, as normas de uma política pautada em princípios mercadológicos têm invadido os ambientes oficiais de educação e expressado o seu domínio de maneira incisiva, sob forte \begin{tabular}{l|l} 
Revista RBBA & Revista Binacional Brasil Argentina
\end{tabular} 
COMUM CURRICULAR NO PROCESSO DE ATUALIZAÇÃO DAS

ESTRATÉGIAS DE DOMINAÇÃO BURGUESA

influência de aparelhos de ação política e ideológica. Esta lógica se estabelece com legitimidade, por meio do amparo de instrumentos legais, como a Constituição Federal, em seu artigo 210, a Lei 9.394/1996 - LDB, em seu artigo 26, as Diretrizes Curriculares Nacionais, em seu artigo 14, além da Lei 13.005/2014 que preveem a formulação da BNCC, a qual, ao adotar a perspectiva da chamada pedagogia das competências, de maneira explícita, privilegia uma formação rudimentar, minimalista e fragmentada, voltada tanto para o mercado de trabalho, quanto para o trabalho precarizado e até mesmo para o desemprego, de modo a atualizar as formas de atendimento às demandas de reprodução do capital em sua luta pelo desmonte dos direitos sociais.

Com isso, a visão de mundo de uma minoria tende a se sobrepor, de maneira legítima, generalizante e naturalizada, como única via possível e, portanto, inevitável. Assim, tal política contribui, sobremaneira, para o processo de enraizamento das ideologias dominantes e para o movimento de perpetuação do status quo, mas não só isso. A aprovação da BNCC e a sua implementação representam a abertura de um leque gigantesco de oportunidade de negócios aos grupos empresariais do setor educacional e uma alternativa fundamental na disputa pelo fundo público. Não é fortuito o fato de as principais empresas brasileiras do campo educacional (Anhanguera Educacional, Estácio de Sá, Kroton Educacional, Grupo Pitágoras e Sociedade Educacional Brasileira (SEB), controladora do COC), a partir do ano de 2007, terem lançado as suas ações na bolsa de valores e, com isso, buscado ampliar a sua capacidade de acumulação privada da riqueza socialmente produzida (OLIVEIRA, 2009).

Ademais, é possível inferir, com base em informações do Fundo Nacional de Desenvolvimento da Educação - FNDE, que o Programa de Financiamento Estudantil - FIES ${ }^{\text {vi }}$, estratégia usada por esses e outros grupos empresariais, em associação com a sociedade política, para capturar parte significativa do fundo público destinado à educação superior, alcançou um certo ponto de saturação. Isto porque o nível de inadimplência tem crescido nos últimos anos, principalmente em razão dos reflexos da crise econômica de 2008 que, entre outros efeitos, corroborou a ampliação do número de desempregados no país e, com isto, muitos dos compromissos financeiros efetivados pela classe que vive da venda de sua força de trabalho deixaram de ser cumpridos.

De acordo com Raposo (2020), em artigo publicado no site Movimento Econômico: 
Após experimentar o seu auge em 2014, o Fies, Sucessor do Crédito Estudantil, alcançou $60 \%$ de inadimplência em seus 900 mil contratos ao longo de $2019 \mathrm{e}$ o desinteresse dos estudantes devido às mudanças em seu conceito. As mudanças retiraram o aspecto social da iniciativa, tornando o Fies inacessível para boa parcela dos estudantes que precisam do apoio do poder público para ter acesso à educação superior. Isso fez com que as matrículas encolhessem nas instituições de ensino superior, fazendo o ensino básico ganhar relevância, sobretudo o ensino médio. Colégios com grandes quantidades de alunos e tradição se destacam. "O mercado está aquecido e não importa muito se a escola tem ou não excelente entrega no Enem. O que interessa é ganhar espaço", diz um empresário do setor de educação de Pernambuco [...]. A valorização do mercado da educação básica, também levou a uma movimentação inversa: grandes grupos que atuam no ensino superior, passaram a se voltar para esse segmento, como a Kroton Educacional e a Estácio.

Dessa forma, o empresariado, responsável pelos investimentos no ensino superior privado, tem buscado ampliar os seus investimentos na Educação Básica e, para tanto, a aprovação da Base Nacional Comum Curricular se revelou parte fundamental dessa estratégia. Isto se justifica pelo fato de a Base suscitar uma série de investimentos públicos e privados, de diferentes campos, para a sua realização. Como exemplo, cita-se o amplo mercado de livros didáticos, de consultorias, de formação de professores, dos sistemas de avaliação, de projetos e plataformas educacionais, de diferentes materiais didáticos e paradidáticos, entre outros tantos nichos de mercado, criados com vistas à captura de parte importante do fundo público. Além disso, outra forma de alcançar o fundo público pela iniciativa privada se refere às renúncias, isenções e deduções fiscais, motivações importantes para a constituição das chamadas fundações e associações sem fins lucrativos, as quais são contempladas por esses e outros benefícios públicos, incluindo o recebimento de subvenções, auxílios e doações (CASIMIRO, 2018, p. 127).

Com tantos interesses em jogo, fica fácil entender as razões que levaram o aparelho privado de hegemonia, Movimento pela Base, em íntima articulação com a sociedade política, a exigir a aprovação imediata da BNCC pelo Conselho Nacional de Educação - CNE, mesmo diante de muitos "protestos de entidades ligadas aos professores" e do pedido de vista, feito pelas conselheiras Aurina de Oliveira Santana, Malvina Tania Tuttman e Márcia Ângela da Silva Aguiar, as quais solicitavam mais tempo para analisar a proposta da Base (BATISTA, 2017). Apesar dos questionamentos, uma semana depois, no dia 15 de dezembro de 2017, o CNE aprovou a BNCC da educação infantil e do ensino fundamental e a encaminhou para a homologação do 
COMUM CURRICULAR NO PROCESSO DE ATUALIZAÇÃO DAS

ESTRATÉGIAS DE DOMINAÇÃO BURGUESA

então Ministro Mendonça Filho, realizada cinco dias depois, num movimento profundamente aligeirado e autoritário.

Cabe pontuar ainda o fato de que na mesma gestão do Ministro Mendonça Filho foi publicado o Decreto de 27 de junho de 2016 e a Portaria $N^{\circ}$ 577, de 27 de abril de 2017, que trataram, respectivamente, da recomposição do Conselho Nacional de Educação e do Fórum Nacional de Educação, transformando estas instâncias em órgãos de governo. Tais medidas despóticas revelaram-se muito importantes para facilitar a posterior aprovação da política curricular expressa pela Base, haja vista o perfil defensor de tal política dos novos integrantes dessas importantes entidades. Atualmente o ex-ministro integra a equipe de consultores da Fundação Lemann, o que sinaliza uma espécie de retribuição aos serviços prestados enquanto esteve na condição de importante agente político.

De modo complementar, a expressão mais evidente desses acentos autoritários se deu com o processo de alteração curricular imposto à última etapa da Educação Básica, por meio da Medida Provisória 746/2017, que deu origem à Lei n n 13.415/2017 e consolidou a Reforma do Ensino Médio (COSTA e SILVA, 2019). Este movimento particular ajuda a compreender as razões que levaram à fragmentação na formulação e homologação dessa política expressa pela BNCC, visto que os anos finais da Educação Básica foram tratados separadamente, com especificidade, apesar de integrarem o mesmo projeto forjado pela classe dominante e suas frações. Com efeito, tratou-se de um movimento ainda mais abrupto, que prescindiu de qualquer participação ampla por parte da sociedade civil e revelou traços muito mais coercitivos do que as estratégias e táticas usadas ao longo da dinâmica de definição da forma e do conteúdo da Educação infantil e do Ensino Fundamental. Destarte, a despeito dos vários posicionamentos contrários, no dia 14 de dezembro de 2018 à BNCC se integraram as novas orientações curriculares para o Ensino Médio.

Nessa perspectiva, os pressupostos do processo de definição e implementação da BNCC sinalizam medidas antidemocráticas, fundamentadas no elevado grau de autoritarismo praticado pelo governo ilegítimo de Michel Temer (2016-2018). Processo caracterizado pela ausência de participação efetiva de professores e estudantes na definição desse documento curricular, apesar da retórica oficial anunciar o contrário, especialmente quando se expõe os dados da consulta pública sobre o BNCC, aberta pelo Ministério da Educação (MEC) em plataforma online, que entre outubro de 2015 e abril de 2016 recebeu mais de 12 milhões de contribuições (BRASIL, 2016). Conquanto, o que não se explicita é que a chamada 
COMUM CURRICULAR NO PROCESSO DE ATUALIZAÇÃO DAS

ESTRATÉGIAS DE DOMINAÇÃO BURGUESA

"participação" foi, na prática, parcial, pois ignorou as críticas produzidas por especialistas do campo educacional, formuladas ao longo das diferentes versões do documento. Nessa direção, Mônica Ribeiro, professora da Universidade Federal do Paraná, aponta que a versão aprovada da Base consolidou um documento "totalmente novo", em razão de ter sido produzido por outros especialistas, diferentes daqueles que participaram das primeiras etapas (ANTUNES, 2017), o que comprova a dinâmica centralizada de formulação do documento. Com isso, nessa articulação entre o MEC e o Movimento pela Base, o processo de implementação da BNCC, e isto inclui a Reforma do Ensino Médio foi fortalecido e segue em vias de consolidação no âmbito das redes e sistemas de ensino de todo o país.

Como se vê, o Estado, ora atuando de forma mais incisiva, através da imposição de medidas amparadas pela força da legislação, de modo a consolidar, em muitos casos, medidas extremamente autoritárias ${ }^{\mathrm{vii}}$, ora servindo-se das estratégias e táticas de produção de consenso, implementou uma série de reformas sociais com vistas ao favorecimento das classes e frações da classe burguesa, apesar das constantes lutas travadas pelos trabalhadores em sua tentativa de resistência. Esse movimento, alargado com o exponencial ascenso do rentismo, ocorrido a partir da abertura democrática do país ao final dos anos 80, segue adquirindo contornos cada vez mais vis, cuja expressão mais recente é traduzida pela própria eleição do presidente, agora sem partido, Jair Messias Bolsonaro (2019 - atual).

As políticas do atual governo, pautadas no ultraliberalismo associado à extrema direita conservadora tem arrastado uma multidão de trabalhadores à miséria e, com isso, promovido a ampliação da vulnerabilidade social, de forma, sobretudo, violenta e irresponsável, haja vista a concentração de riqueza proporcionada principalmente aos grupos empresariais do capital financeiro, às custas de renovadas formas de expropriação.

Assim, essa dinâmica de expropriação, aprofundada nos últimos quatro anos, fez o Coronavírus encontrar uma sociedade devastada pela violência de uma "nova direita" ultraliberal conservadora (CASIMIRO, 2018), cujas medidas, configuradas pela combinação de força e consenso, atropelam os direitos sociais e, por tabela, lançam centenas de milhares de pessoas na informalidade e na miséria. Prova disso se expressa no resultado da pesquisa realizada pelo Instituto Brasileiro de Geografia e Estatística - IBGE em 2019, que indica o mais expressivo avanço do número de trabalhadores informais no país dos últimos anos (RENAUX, 2019). De modo complementar, o mesmo instituto registrou em 2019 a existência de mais de 
COMUM CURRICULAR NO PROCESSO DE ATUALIZAÇÃO DAS

ESTRATÉGIAS DE DOMINAÇÃO BURGUESA

13 milhões de brasileiros em condições de miserabilidade, ou seja, "pessoas sobrevivendo com até 145 reais mensais" (JIMÉNEZ, 2019).

No que diz respeito às políticas de educação, o ano de 2019 registrou a diminuição de mais de sete milhões de reais, em relação ao ano anterior, passando de 4,9 para 4,2 bilhões de reais destinados à educação (MAZIEIRO, 2019). A previsão para este ano é um corte de $50 \%$ deste último montante, o que expõe a intenção do governo de acelerar a privatização do ensino público do país. Além disso, nas palavras de Brescianini (2019), “o orçamento aprovado pelo Congresso para 2020 é o mais restritivo dos últimos anos" e demonstra o quanto o governo está comprometido em aplicar uma profunda disciplina fiscal, através da qual a sociedade política punciona a maior parte dos recursos públicos para transferi-los aos agentes do capital monetário. A previsão é de que mais de $50 \%$ do orçamento seja destinado ao serviço da dívida. Trata-se "do maior volume gasto na história do país em manutenção da dívida pública" (BRESCIANINI, 2019). Com isso, se aprofunda um processo violento, que combina concentração de capitais e permanentes ataques aos direitos sociais.

\section{CONSIDERAÇÕES FINAIS}

Diante da análise realizada ao longo deste artigo, é possível sinalizar que a refuncionalização do Estado, sobretudo no contexto de ascenso do neoliberalismo e, por conseguinte, da hegemonia do capital financeiro, é derivada da própria necessidade de atualização das estratégias de dominação da classe burguesa, ocorrida a partir dos anos 70, e está pautada pela violência como potência econômica. Tratam-se de permanentes e sistematizadas investidas contra os interesses da classe que vive de sua força de trabalho, manifestando-se, de forma autoritária, através do avanço de um conjunto de reformas nas políticas econômicas e sociais, que têm por corolário a apropriação da maior parcela do fundo público por parte das classes e frações de classe no poder e o aumento da precarização das condições de vida dos trabalhadores.

No campo educacional, a dinâmica de renovação dos mecanismos de atualização e reposição da hegemonia burguesa e o complementar avanço do autoritarismo foram evidenciados a partir dos pressupostos que envolveram o movimento de definição, aprovação e implementação da Base Nacional Comum Curricular - BNCC. Um processo configurado pela articulação entre sociedade política e sociedade civil, numa clara manifestação da própria 
COMUM CURRICULAR NO PROCESSO DE ATUALIZAÇÃO DAS

ESTRATÉGIAS DE DOMINAÇÃO BURGUESA

ampliação do Estado. Nesse sentido, foi demonstrada a atuação de aparelhos privados de hegemonia, atrelados a grupos empresariais, cujos objetivos se encontram, entre outras coisas, na renovação e maior adesão da ideologia burguesa pelo conjunto da sociedade, assim como na ampliação das taxas de acumulação a partir do aumento da produtividade no trabalho, além da (re)apropriação da mais-valia, via captura do fundo público, seja por meio da oferta de serviços e produtos ao poder público ou pela via das isenções fiscais.

Nessa perspectiva, viu-se como a complexidade alcançada pela sociabilidade capitalista promoveu a constituição de novos arranjos econômicos, políticos e ideológicos, reverberados no campo da luta de classes como manifestação de interesses divergentes e contraditórios. A compreensão dessa realidade passa pelo necessário debate acerca do papel do Estado, em seu sentido mais amplo, e dos sujeitos políticos coletivos que disputam sua direção. Por isso mesmo, a educação exerce uma função de destaque na luta pela construção de outro projeto hegemônico, fundamentado não mais na exploração e alienação do trabalho, mas na sua condição ontológica e na emancipação social.

\section{REFERÊNCIAS}

ANTUNES, André. A quem interessa a BNCC?. EPSJV/Fiocruz. 2017. Disponível em: http://www.epsjv.fiocruz.br/noticias/reportagem/a-quem-interessa-a-bncc. Acesso em: 17 de junho de 2020.

ANTUNES, Ricardo; PINTO, Geraldo Augusto. A fábrica da educação: da especialização taylorista à flexibilização toyotista. São Paulo: Cortez, 2017.

BATISTA, Larissa. Votação da nova Base Nacional Comum Curricular é adiada após pedido de vista. Disponível em: https://g1.globo.com/educacao/noticia/votacao-da-nova-basenacional-comum-curricular-e-adiada-apos-pedido-de-vistas.ghtml. Acesso em: 30 de abril de 2020 .

BOSCHETTI, Ivanete. Os custos da crise para a política social. In: BOSCHETTI, Ivanete; BEHRING, Elaine; SANTOS, Silvana Mara de Morais dos; MIOTO, Regina Célia Tamaso (Orgs.). Capitalismo em Crise: Políticas Sociais e Direitos. São Paulo: Cortez, 2010.

COSTA, Marilda de Oliveira; SILVA, Leonardo Almeida da. Educação e Democracia: Base Nacional Comum Curricular e Novo Ensino Médio sob a Ótica de Entidades Acadêmicas da Área Educacional. Revista Brasileira de Educação. Vol. 24. Rio de Janeiro, 2019.

BRASIL. Ministério da Educação. PNE em Movimento. Consulta pública sobre Base Nacional Comum recebeu mais de 12 milhões de contribuições. Disponível em: http://pne.mec.gov.br/noticias/473-consulta-publica-sobre-base-nacional-comum-recebeu-ais- 
A REFUNCIONALIZAÇÃO DO ESTADO E A POLÍTICA DA BASE NACIONAL

COMUM CURRICULAR NO PROCESSO DE ATUALIZAÇÃO DAS

ESTRATÉGIAS DE DOMINAÇÃO BURGUESA

de12milhoesdecontribuicoes\#: :text=Mais\%20de\%2012\%20milh\%C3\%B5es\%20de\%20cont ribui\%C3\%A7\%C3\%B5es.,de\%20toda\%20a\%20sociedade\%20brasileira. Acesso em: 08 de junho de 2020.

BRESCIANINI, Carlos Penna. O Orçamento Aprovado pelo Congresso para 2020 é o mais Restritivo dos Últimos Anos. Agência Senado. 2019. Disponível em: https://www12.senado.leg.br/noticias/materias/2019/12/27/orcamento-aprovado-pelocongresso-para-2020-e-o-mais-restritivo-dos-ultimos-anos. Acesso em: 30/04/2020.

CASIMIRO, Flávio Henrique Calheiros. A nova Direita: aparelhos de ação política e ideológica no Brasil contemporâneo. 1 ed. São Paulo: Expressão Popular. 2018.

CASTELO, Rodrigo. Supremacia rentista no Brasil neoliberal e a violência como potência econômica. Universidade e Sociedade, ano XXVII, n.60, p. 58-71, julho de 2017.

FARIZA, Ignácio. Pandemia de Coronavírus Mergulha Economia no Desconhecido. El País, 2020. Disponível em: https://brasil.elpais.com/economia/2020-03-15/pandemia-docoronavirus-mergulha-a-economia-no-desconhecido.html/ Acesso em: 28 de abril de 2020.

FONTES, V. O Brasil e o capital-imperialismo: teoria e história. 2.ed. Rio de Janeiro: EPSJV/Editora UFRJ, 2010, 388p.

FREITAS, Luiz Carlos de. A reforma empresarial da educação: nova direita, velhas ideias. 1 ed. São Paulo: Expressão Popular, 2018.

GRAMSCI, A. Cadernos do Cárcere - Volume 3: Maquiavel, notas sobre o Estado e a política. Rio de Janeiro: Civilização Brasileira, 2000.

HARVEY, David. Condição Pós-moderna. 12 ed. São Paulo: Loyola, 2016.

JIMÉNEZ, Carla. Extrema pobreza sobe e Brasil já soma 13,5 milhões de miseráveis. EL PAÍS, 2019.2 Disponível em: https://brasil.elpais.com/brasil/2019/11/06/politica/1573049315_913111.html. Acesso em: 28 de abril de 2020.

LUPATINI, Márcio. Crise do Capital e dívida pública. In: SALVADOR, Elivásio; Behring, Elaine; BOSCHETTI, Sara Granemann. Financeirização, fundo público e política social. São Paulo: Cortez, 2012.

MARX, K. O capital: crítica da economia política. Livro 1. O processo de produção do capital. Volume II. Rio de Janeiro: Bertrand Brasil, 1989.

MONTAÑO, C; DURIGUETTO, M.L. Estado, classe e movimento social. 3.ed- São Paulo: Cortez, 2011. - (Biblioteca básica de serviço social; v.5).

MÉSZÁROS, István. A Educação para além do Capital. São Paulo: Boitempo, 2005.

NEVES, Lúcia Maria Wanderley. Educação e política no Brasil de hoje. $4^{\text {a }}$ ed. São Paulo, Cortez, 2005. 
OLIVEIRA, Romualdo Portela de. A transformação da educação em mercadoria no Brasil. Educ. Soc. vol.30 no.108 Campinas Oct. 2009.

\section{RAPOSO, Patrícia. Fundos de Investimento Miram na Educação Básica. Movimento Econômico, 2020. Disponível em:} https://www.cbnrecife.com/movimentoeconomico/artigo/fundos-de-investimento-miram-naeducacao-basica. Acesso em: 01 de maio de 2020.

RENAUX, Pedro. Desemprego cai para 11,8\% com informalidade atingindo maior nível da série histórica. IBGE, 2019. Disponível em: https://agenciadenoticias.ibge.gov.br/agencia-noticias/2012agencia-de-noticias/noticias/25534-desemprego-cai-para-11-8-com-informalidade-atingindomaior-nivel-da-serie-historica. Acesso em: 28 de abril de 2020.

ROMÃO, Wagner de Melo. Políticas Públicas e Democracia Participativa: avanços e limites das conferências nacionais no Brasil. São Paulo: Friedrich-Ebert-Stiftung (FES), 2014.

SANTOS, Aline Veiga dos. A hegemonia do capital na rede de governança do Fundo de Financiamento Estudantil (Fies) / Aline Veiga dos Santos - 2018. 292 f.: il.; $30 \mathrm{~cm}$ Tese (Doutorado) - Universidade Católica de Brasília, 2018. Orientação: Profa. Dra. Ranilce Guimarães-Iosif

SAVIANI. Dermeval. Sistema Nacional de Educação e Plano Nacional de Educação. Campinas: Autores Associados, 2014.

VIEGAS, Elis Regina dos Santos. O Mercado da formação continuada de professores no Brasil: a presença do empresariamento social privado. 2019. $328 \mathrm{f}$. Tese (Doutorado em Educação) - Faculdade de Ciências Exatas e Tecnologia, Universidade Federal da Grande Dourados, Dourados, 2019.

WORLD HEALTH ORGANIZATION. Coronavirus Disease - Situation Report 148. Genebra: WHO; 2020. Disponível em: https://www.who.int/docs/defaultsource/coronaviruse/situation-reports/20200616-covid-19-sitrep-148-draft.pdf?sfvrsn=9b2015 e9_2. Acesso em: 16 de novembro de 2020.

\section{Notas}

${ }^{i}$ Entre 2003 e 2013 os espaços de participação social, com destaque às Conferências de Políticas Públicas "se afirmaram como ambientes de abertura ao diálogo e ao convencimento entre as diversas partes que as compõem". Nesse sentido, apesar de se questionar a relação entre a consulta à sociedade e "a efetividade das decisões na execução de políticas públicas", a ampliação dos espaços participativos criou a sensação de que as grandes decisões governamentais passavam antes por um processo dialógico e de negociação mais abrangentes (ROMÃO, 2014).

ii Segundo Virgínia Fontes (2010), as expropriações primárias se referem à manutenção e ampliação da clássica expulsão de trabalhadores rurais do campo, resultando no impositivo movimento de urbanização crescente. Todavia, por emergirem em um novo contexto, apresenta traços característicos próprios. De modo complementar, aprofundam-se e se atualizam às formas de destruição dos direitos sociais, historicamente conquistadas expropriações secundárias, derivadas da ascensão do neoliberalismo pelo mundo. 
iii Em 1995, no decurso da gestão FHC e sob a liderança do então Ministro da Administração Federal e Reforma do Estado, o Senhor Bresser-Pereira, o Brasil implementou uma série de reformas administrativas, sob a justificativa de se construir um Estado mais eficiente. Para tanto, a lógica empresarial gerencialista passou a ser adotada como princípio fundamental da chamada "nova" administração pública, sobrepondo-se ao "obsoleto regime burocrático", até então, vigente no país. Por essa via, os aparelhos governativos do Estado assumiram uma postura de descentralização, de redistribuição (ou transferência) de responsabilidades entre União, Estados e Municípios, em consonância com os ditames do neoliberalismo, difundidos, primordialmente, pelas principais agências multilaterais.

iv O Estado integral, na concepção gramsciana, deve ser associado a "um equilíbrio da sociedade política com a sociedade civil" (ou hegemonia de um grupo social sobre toda a sociedade nacional, exercida através das organizações ditas privadas, como igrejas, sindicatos, as escolas, etc.) (GRAMSCI, 2011, p. 272). Em outros termos, Gramsci considera que por 'Estado' deve-se entender, além do aparelho de governo, também o aparelho 'privado' de hegemonia ou sociedade civil.

v Segundo o próprio movimento, trata-se de um "Grupo não governamental que, desde 2013, reúne entidades, organizações e pessoas físicas, de diversos setores educacionais, que têm em comum a causa da Base Nacional Comum Curricular".

vi Programa criado em 1999 pelo então Presidente Fernando Henrique Cardoso, tendo em vista a oferta de financiamento de cursos de graduação privados aos estudantes com matrículas efetivas. Ao longo dos subsequentes governos Lula da Silva, o FIES foi reformulado e ampliado, o que favoreceu a transferência de recursos públicos à iniciativa privada.

vii O Ministério da Educação, como entidade representante da sociedade política, em íntima associação com organizações da sociedade civil de cunho empresarial, atuou de forma incisiva no processo de formulação e implementação da BNCC, numa clara manifestação de sua faceta autoritária, que teve como finalidade, enfraquecer e/ou anular a atuação de forças contrárias ao projeto atualizado de dominação da classe burguesa, manifesto pela Base 